\title{
ESCRIBIENDO EL SILENCIO: LA CONTEMPLACIÓN POÉTICA DE SARA PUJOL
}

\author{
CANDElas Gala \\ Wake Forest University
}

La lectura de dos de los libros que Sara Pujol Russell ha publicado en castellano, El fuego tiende su aire (1999) e Intacto asombro en la luz del silencio (2001), supone la entrada en un discurso poético innovador y complejo tanto en contenido como en forma ${ }^{1}$. Manuel Mantero llama «anómalos» a los versos de estas colecciones principalmente por su extensión, ya que incluyen de quince a veinte sílabas y fluyen en composiciones que se suceden como si fueran secciones de un solo poema continuado (115). Los epígrafes y citas que acompañan cada libro y sus distintas partes marcan el lugar de estas colecciones en la tradición cultural, además de identificar las preferencias filosóficas y artísticas de la autora. El lector crítico que se acerca a esta obra se encuentra con un texto consciente de su identidad de signo artístico y de su contenido filosófico y carga existencial.

La poesía de Pujol invita a una contemplación meditativa que busca las correspondencias entre los diversos elementos de la realidad como clave para acceder a un conocimiento superior. Para ello, su lenguaje se mueve en los bordes entre la voz y el silencio, el arte y la naturaleza, el sentido y el vacío, la identidad y la diferencia, en lo que Julia Kristeva reconoce como el gesto de semejanza que acalla la diferencia del signo ligando su «unidad significativa al objeto significado». Dicha «similización» facilita «un acuerdo de separaciones» o diferencias que lleva a «una identificación más allá» de la disyunción existente entre signo y entorno $(107,108-$ 109). Es en ese movimiento de superación de la disyunción, síntesis a punto ya de disolverse, donde se enfoca la lectura en este ensayo.

\footnotetext{
${ }^{1}$ En 2004 ha salido su tercer libro de poesía, Para decir si a la carencia, sí a la naranja, al azafrán en el pan. En catalán Sara Pujol ha publicado Inquietud de pleniluni, por el que recibió el «Premi Recull» en 1980. En 2001 se publicó Il fuoco del silenzio [El fuego del silencio], una antología bilingüe a cargo de Emilio Coco que incluye poemas procedentes de sus dos libros en castellano.
}

Rlit, LXVII, 133 (2005), 147-164 
Por su extensión, falta de organización estrófica y envergadura verbal, los versos de estos libros se acercan a la forma de la silva, lo cual se reitera en la gran profusión de imágenes y alusiones por las que el lector debe moverse como si se tratara de una selva o bosque frondoso - significado etimológico de la palabra «silva»- en busca de un claro o sentido. En el proceso de la lectura, los ojos deben seguir el movimiento de las palabras a lo largo de los versos reproduciendo el movimiento de la mente en la contemplación interior. En este sentido, Pujol sigue la línea de poesía meditativa que, con nombres como San Juan de la Cruz, Sta. Teresa de Jesús y Fray Luis de Granada, entre otros, funde, en la intensidad del acto creador, lo sensorial con la capacidad intelectual ${ }^{2}$. Su texto se coloca, así, en la tradición que desde el humanismo renacentista hace de la poesía y del arte medios de recobrar la fuente de la sabiduría. Los ecos neoplatónicos son difíciles de negar y, en el caso de Pujol se aprecian en su confesada admiración por Plotino y en su búsqueda de unidad y armonía en la Naturaleza.

La tendencia a la confluencia de lo dispar se refleja en los títulos de ambas colecciones. En El fuego tiende su aire, la poeta lanza el fuego de su amor y arte en el aire entorno, en el que nos hallamos como lectores, en un gesto de expansión que, a la vez, arriesga extinguirse en ese mismo gesto, mientras que la unión de luz y silencio, en Intacto asombro en la luz del silencio, recurre a la sinestesia para articular esa síntesis entre realidades distintas. Sugiere también el asombro o admiratio de una experiencia extática ubicada en un espacio solitario y de reflexión, según se confirma en los títulos de las dos partes del libro, «Soledad de la luz» y «Rosa abierta en silencios» ${ }^{3}$. La tendencia «similizante» adquiere su mejor expresión en el amor, «un nombre que tiene todos los nombres», según indica uno de los epígrafes a El fuego, y que correspondería a la forma como verdad esencial donde se funde la multiplicidad sensorial. Pero, según se ilustra en la cita de Percy B. Shelley al Libro I, «La Poesía es una espada de luz, siempre desnuda, que consume la vaina que intente contenerla», el

\footnotetext{
${ }^{2}$ En su estudio The Poetry of Meditation, Martz describe la meditación como un fenómeno de gran intensidad donde lo sensorial y lo intelectual se funden «in a moment of dramatic, creative experience» (1).

${ }^{3}$ Libro I de Intacto asombro se titula «Agua en la piedra, sueño del silencio» y Libro II, «Iniciación a la noche, búsqueda de la luz». El encuentro de «agua» y «piedra», como sueño del silencio, fusiona lo sólido con lo líquido, la eternidad con el fluir temporal, la voz viva y su petrificación en la forma artística, mientras que la noche, según la tradición mística, es el camino hacia la luz. El silencio en la búsqueda de la palabra poética, como la luz dentro de la oscuridad, reflejan el entendimiento del quehacer de la escritura como proceso que va de lo sensible a lo inteligible, o de la unidad del signo a la cosa, en intercambio constante. El asombro que produce la contemplación del silencio implica, para Dauenhauer, un rendirse («yielding») al reconocer la superioridad de su contenido frente a la propia finitud.
} 
fuego poético, como el amor, es una fuerza desnuda y elemental cuya agudeza no puede constreñirse en una forma $\mathrm{fija}^{4}$. La misma idea se contiene en la cita de Juan Ramón Jiménez que precede al libro II: «Yo concibo el espíritu como el olor de una rosa; que siendo ella tan pequeña por mayor que sea, él puede hacer una rosa del tamaño de la luz del día o de la sombra de la noche». Como en la cita de Shelley, la poesía/rosa excede a la forma que la contiene, apuntando al foco de esta poesía, es decir, la dinámica del signo en su movimiento entre voz y silencio, diferencia y semejanza, arte y naturaleza, lo sensorial y lo intelectual.

Por eso, la identidad de la hablante se ubica en la convergencia de luz y silencio, según indica la cita que precede a Intacto asombro, «Al silencio que me crea, a la luz que me sostiene», mientras que el epígrafe de Plotino para el Libro II se refiere al enlace entre lo de dentro y lo de fuera: «Es que el hombre perfecto va ya camino de la unidad y de la serenidad, no sólo de lo exterior, sino aún de la serenidad consigo mismo. Y todo le es interior ${ }^{5}$. Junto con el filósofo presocrático, Pujol insiste en la continuidad y armonía de de los diversos elementos de la Naturaleza entre sí y en su relación con la mente contempladora. Sin embargo, la cita de Juan Ramón Jiménez al Libro II: «Pero la belleza vuelve / a desnudarme otra forma», torna desde la unidad presocrática a la dinámica de una realidad donde las formas se encuentran en un movimiento infinito de especularidad. La cita final de María Zambrano reconoce ese movimiento en la realidad temporal: «Se escribe para reconquistar la derrota sufrida siempre que hemos hablado largamente». Procedente de la sección titulada «Por qué se escribe» en Hacia un saber sobre el alma, la cita sugiere el poder de la palabra para reaccionar ante las circunstancias y vencer el momento, pero también su dispersión en el curso temporal (31-32). La escritura, en cambio, trae consigo un recogimiento en torno al centro de nuestro ser, da perdurabilidad a la voz y nos salva del tiempo. Esta serie de citas y epígrafes enmarcan los libros de Pujol como un escenario donde representar la búsqueda de la semejanza en la diferencia y, en última instancia, del silencio a través de la palabra misma.

La mayoría de los poemas son una contemplación centrada en el corazón como sede desde donde irradia el movimiento hacia el otro y hacia donde todo se vuelve (Zambrano, Claros del bosque 59, 63, 72) ${ }^{6}$. «Contemplación

\footnotetext{
${ }^{4}$ «Poetry is a sword of lightning, ever unsheathed, which consumes the scabbard that would contain it» (Shelley 47).

${ }^{5}$ Plotino elabora sobre el principio de armonía entre los distintos grupos de la realidad que, aunque dotados cada uno de su propia voz, «all is brought into accord, into an ordered system, for the universal purpose, by the ruling Reason-Principle» (162).

${ }^{6}$ Tanto Mantero como Uceda en el antiprólogo y epílogo al primer libro, respectivamente, señalan la importancia en Pujol de la contemplación, de su fusión con lo contemplado y de la serenidad que procede de ella. La misma Pujol indica en las «Deu-
} 
primera» (19), poema de apertura de $E l$ fuego, comienza con frases breves y escuetas que parecen contener la plenitud del ser y del sentido: «Amanece febrero. Mediodía. El tiempo no se sucede». El polisíndeton de la conjunción «y» (versos 2-7) sugiere acumulación gozosa que, junto con las exclamaciones («qué belleza»; «Qué feliz»; «iArmonía!»), la contemplación recíproca del agua/tiempo y su tregua, y la repetición de $m i, m e, a$ mí, de mí, sugiere el yo como centro de emanación hacia fuera y de retorno hacia el interior. El corazón se proyecta en el exterior cuyos campos de heno se trasladan a la interioridad subjetiva. Mediante los deícticos «esta savia», «esta fuerza», la hablante establece la relación gestual que supera la distancia entre el centro del yo y el entorno. La repetida «inmovilidad» «ante el mundo» y «del mundo» insiste en la plenitud del estado descrito, estado extático y centrado en el yo o corazón, lugar privilegiado de revelación o «claro del bosque» (Amorós, «La metáfora del corazón» 61).

El pensamiento de María Zambrano, de quien procede la expresión «claro del bosque», así como el de otros autores mencionados en epígrafes y citas, resuena en este primer poema y a lo largo del libro. El asombro extático del poema refleja el amor que, como indica Plotino, se encuentra en el reconocimiento de una simpatía entre los distintos elementos de la realidad: «It is sound...to find the primal source of Love in a tendency of the Soul towards pure beauty, in a recognition, in a kinship, in an unreasoned consciousness of friendly relation» (191). En su búsqueda de lo bello y verdadero, al poeta le atañe apreciar la relación de simpatía que subyace a todo lo existente y, como indica Shelley, darla expresión en el poema: «to be a poet is to apprehend the true and the beautiful, in a word, the good which exists in the relation, subsisting, first between existent and perception, and secondly between perception and expression» (30). Se da aquí un conocimiento logrado mediante la contemplación interior o diálogo silencioso del alma consigo misma que Zambrano llama «razón poética», entendiendo por tal la unidad de sentido en la dirección del universo que tiene lugar en la fusión del pensar y del sentir como parte de la contemplación meditativa (Hacia un saber 13) ${ }^{7}$.

Este poema responde a lo que en el proceso meditativo Martz identifi-

das» (110) que durante los años en que escribió los poemas de su primer libro, el entorno fue el espacio natural de su cuerpo y paisaje espiritual de su alma. Según Uceda, la lectura de estos poemas revela dentro del tiempo la presencia de otro tiempo, el tiempo subjetivo de la memoria y pensamientos que se escapan de la palabra y sólo se asoman a través de los ojos del silencio.

${ }^{7}$ La fusión del pensar y del sentir en la visión de Zambrano se refleja en los poemas de Pujol como medio de lograr el conocimiento y la liberación (18-24). Moreno Sanz señala el papel de Pascal y su «orden del corazón» en el pensamiento de Zambrano quien, en esa base, parece desandar el camino de la filosofía al volverse a sus raíces en lo sagrado y lo poético. Biruté Ciplijauskaitè considera "Contemplación primera» como poema «worhty of being included in every anthology». 
ca como el preludio o «composition of place». En esta fase inicial, y mediante los ojos de la imaginación, el meditante identifica un espacio - «seeing the spot»- donde llevar a cabo la meditación (27). En el poema se trata de un centro de confluencia ocupado por el corazón en un «ahora» o presente pleno donde sujeto y objeto se encuentran en una relación especular de correspondencia mutua ${ }^{8}$. «La palabra es la mirada», pues el signo supera su disyunción con el objeto observado fundiéndose con él, lo que lleva a la constatación de que «Por fin, la unión deseada me ha sido concedida» (19). El estado resultante es de dicha y plenitud: «Mi corazón / henchido de mi alma y mi alma henchida de mi corazón» (19). La palabra/mirada refleja el mundo entorno que, a su vez, devuelve su mirada a la hablante quien afirma: «por primera vez, estoy en ellos y ellos en mí».

La confluencia de múltiples perspectivas en el poema explica su tono de asombro y admiración. El presente converge con el pasado y el futuro y la subjetividad se funde con el entorno que, a su vez, entra a formar parte del paisaje interior. La hablante percibe la armonía cósmica que, por su parte, capta la armonía de la hablante, lo que le hace exclamar, «La música me asombra. Me escucha». El lenguaje como instrumento artístico revela la maravilla del entorno elevando a la hablante hacia la percepción de la armonía o amor entre los diversos elementos de la Naturaleza. Dicha percepción o conocimiento se identifica con la serenidad y, más adelante, con el silencio: «este saberse límite sin nostalgia, / sin esperar nada, serenidad».

Según explica José Angel Valente, la poesía es conocimiento que tiene lugar en el acto creador mismo y no como conocimiento de algo previo al poema (21). Así se evidencia en este poema de apertura y en «Tiempo de luz, tiempo de agua» (20). Ambos dan prueba de la escritura como medio de llegar al conocimiento al perfilar la experiencia mediante las palabras. «Luz. ¡Tanta luz y agua!», proclama al comienzo de «Tiempo de luz, tiempo de agua». Y a medida que va identificando los distintos aspectos de la experiencia, la voz poética se corrige, cincelando las impresiones: «Viene hacia mí [el agua] y yo voy hacia ella, y juntas / ¿dónde vamos?» Sin embargo, la función similizante del lenguaje en estos poemas lleva ya en sí implícita su diferencia, como indica el título «Contemplación primera», sugerencia de otras contemplaciones siguientes donde la mimesis especular se sucede por la disyunción y la sombra.

Así, en «Contemplación segunda» (22), donde se lee: «Contemplo la larga vida de mi corazón y no me hallo. / Contemplo la larga vida de mi

\footnotetext{
${ }^{8}$ El poema articula un orden donde, según explica Culler refiriéndose al estadio especular lacaniano, «subject and object are present to one another in a light which makes posible a specular relationship, a relationship of correspondence: subject reflected in object and object in subject» (The Pursuit 164).
} 
vida y no me encuentro en ella» (22). La pérdida en esa «larga vida» es la que trae consigo el tiempo y la distancia: «La distancia me sigue y se me escapa», admite la hablante. El poema parece hacer eco de la inquietud en el alma que, según Plotino, la llevó a divulgar en el tiempo lo que conoció en su recinto de autenticidad (234). El poema expresa esa inquietud como desconocimiento ya que el tiempo se infiltra en el enlace de signo y entorno descentrando la visión (Kristeva 112-113). La hablante revela su pérdida en una serie de preguntas sobre su identidad, su ser, su espacio y tiempo: «¿Estoy? ¿Quién soy? ¿Quién va? ¿Dónde está mi terreno espacio y mi tiempo?» $\mathrm{O}$ bien, dirigiéndose al lector, constata la distancia entre sus palabras y el otro: «Tú, que en este momento me lees, ¿qué recuerdas de mí?» Reconoce, así, el acto de la escritura, de la presencia de la palabra interponiéndose entre su yo y el entorno. Para recuperar el sentido del ser propio, a modo de anamnesis la hablante se vuelve hacia atrás pues entiende con San Agustín que la memoria es como un campo enorme, palacio espacioso o almacén de imágenes donde es posible encontrarse a sí mismo (214): «No olvidar es detener el tiempo en la piedra y sobrevivir».

La pérdida del centro se expresa como la incapacidad de generar las imágenes o visualizaciones mediadoras del conocimiento, según indica el título «No puedo oírme, no puedo contemplarme» (96) de su segundo libro $^{9}$. Las palabras han perdido su resonancia y no pueden alcanzar la oda, es decir, la elaboración de un canto lírico con que ensalzar la red de correspondencias y relaciones en la naturaleza. Por eso la hablante confiesa ir «entre iniciales, sólo inicios». Ni el loto ni la rosa, flores icónicas del misterio en el oriente y occidente, respectivamente, se le revelan (Cirlot 281). Aunque sueña en «un solo verbo que sólo sea verbo y casa, alacena y alma, y no sólo el vacío creciendo en los límites del verbo», la realidad se le aparece como una serie de formas disolviéndose. En «Lo desnudo en selva oscura» (98), la pérdida adquiere resonancias dantescas: «Caí lenta círculo a círculo». El nombre que ha venido merodeando desde el comienzo de su aventura poética es un «nombre del viento» donde su sentido se disuelve, lo cual se reproduce textualmente en la sucesión de los versos con digresiones y preguntas entre guiones interceptando el fluir del sentido.

No sólo el nombre se pierde en el viento y en el deslizar sinuoso de los versos, sino también el despertar de la sexualidad y experiencia del amor: «viento de los amaneceres / del cuerpo - ¿en qué parte de mi cuerpo encontrarte, amor, mi amor». Su cuerpo, alcancía o vasija hecha de «agua y junco y cuerpo y nada», acumula paradójicamente en el polisíndeton su propio vacío. El nombre ha perdido su capacidad de contener el sentido y

\footnotetext{
${ }^{9}$ Para Shelley la imaginación asocia mientras que la razón disgrega: «Reason respects the differences, and imagination the similitudes of things. [...] Poetry, in a general sense, may be defined to be «the expresión of the imagination» (Shelley 26).
} 
la hablante confiesa: «Entré en mi propio nombre que no me cernía». La llegada de mayo, sin embargo, le trae el calor y resguardo de la tradición artística y cultural en la referencia al fuego de Botticelli, a Gilgamesh y a Van Gogh, donde refugiar la desnudez del nombre y recobrar el sentido. La pérdida en la selva selvaggia dantesca que describe este poema llega a la revelación de que «sólo se opone a la luz la misma luz, el espacio y el tiempo y los sueños del hombre». La luz de la revelación no puede mantenerse permanentemente por las exigencias de la vida, constatación que la hablante comparte con Ficino para quien el elevado estado que se logra mediante la contemplación debe volver, tras unos momentos de perfección, a la esfera de la vida diaria. La hablante del poema vuelve a los campos, a «aquel jardín» que identifica como «la selva oscura en medio de la vida» donde cae sin fuerzas, «círculo a círculo». De esa caída, sin embargo, llega a alcanzar «la luz de las rosas», es decir, la iluminación del misterio. $\mathrm{Si}$ en un principio consideró la posibilidad de mantenerse en la iluminación, con Ficino entiende que la contemplación meditativa es un proceso dialéctico de ascensión y descenso continuos (Kristeller 225-226).

«Origen del verbo, germinación de la tierra» y «Armonía en invierno» (El fuego tiende su aire 26,27), continúan la idea de coexistencia y vaivén entre signo y mundo. En el primer poema, la hablante se pone de rodillas para esculpir en la tierra su llanto del que germina la palabra, el verbo, identificando, así, el origen de la escritura con el dolor humano y con la tierra. "Armonía en invierno» (27) elabora el entendimiento de la palabra como coexistencia de identidad y diferencia: «Sólo os puedo decir que de la locura nace la calma, / de la tristeza, y de su peso, la levedad y la alegría». Y más adelante: «es acuerdo y orden. Es la pura armonía / del ser y el estar inseparables. [...] / ¡Oh, proporción y equilibrio en un instante casi infinito!» La hablante parece haber llegado a la constatación de que en todo signo se halla inherente su opuesto. Sentir y comprender esa coexistencia de opuestos es el don de haber logrado un entendimiento de la vida en su verdad intrínseca ${ }^{10}$.

Por eso, la hablante pide «Un hontanar de palabras» (27), pues la profusión verbal de estos poemas funciona como una red o selva que se debe traspasar para acceder al silencio. Las palabras se extienden en lazos de similitud hacia otros términos aparentemente alejados en sentido, mientras que la variedad de las imágenes, la sinuosa sucesión de los versos, y lo laberíntico de las asociaciones, obligan al lector a seguir una trayectoria mental igualmente curvilínea para poder atravesar el enigma del lenguaje $\mathrm{y}$, superando su urdimbre, avanzar hacia el otro lado, el del silencio. Las

\footnotetext{
${ }^{10}$ Pujol comparte con Zambrano la idea de que amor y conocimiento están más unidos de lo que parece a primera vista: «El amor nacido en la dispersión de la carne, encuentra su salvación porque sigue el camino del conocimiento...llega al mismo fin que él por diferente camino...el de la manía o el delirio» (Filosofía y poesía 66).
} 
palabras de Pujol son «reveladoras» no porque se entiendan, sino porque, según indica Zambrano, son «reveladoras simplemente de la palabra misma; del misterio de la palabra». Por eso, su frondosa selva verbal no viene cargada de comunicación expresiva sino «como habiéndose escapado de algún lugar de donde la palabra rara vez suele venir: de ese remoto silencio, fondo, horizonte, océano de silencio» (El sueño creador 68-69). No hallamos en esta poesía los recursos retóricos típicamente asociados con el silencio, así el litote, la elipsis, los sobreentendidos, sino otros que como el polisíndeton, símil, anáfora, apóstrofe, hipálage y oxímoron aumentan el tupido verbal como si en esa urdimbre se quisiera atrapar lo que está más allá y que se mantiene irreducible. En este sentido, la poética de Pujol coincide con la experiencia liminar de lo indecible en busca del decir y que José Angel Valente elabora con relación a los místicos (Las palabras de la tribu 66).

Así se evidencia en «Creación de la luz» (49). Este poema se construye en torno al símil anafórico «como» repetido en cada uno de los versos de la primera mitad. Como el lirio, la abeja, el fuego, el diluvio y la música se vuelven hacia el posible origen del que partieron buscando entender lo contradictorio de su naturaleza, «así, mi corazón», afirma la hablante, busca descifrar el signo de la rosa que, a su vez, «busca la fuente que la ha de liberar del tiempo y del sueño» (49).

El análisis de Julia Kristeva sobre la anáfora ilumina su uso en el texto de Pujol. Entendida etimológicamente como un movimiento a través de un espacio, la anáfora designa «una presencia continua [...], un desplegarse por todo el espacio, a través y por doquier». Por ello, la anáfora se diferencia de la relación «estática, didáctica y finitizante del signo» pues vincula el texto con todo lo que está fuera de la lengua, más allá de la superficie lingüística pero que no puede pensarse más que a través de la lengua (Kristeva 106). La anáfora lleva a cabo «el salto de lo trazado hacia, sobre, a través», cubriendo el vacío que separa el deíctico del objeto apuntado. Destierra, así, la ausencia pues concentra el tiempo y el espacio en el vacío que une dos inscripciones. Por tanto, «designa lo que es suplementario a lo escrito, mudo pero siempre allí». Mediante el símil anafórico, el poema de Pujol articula el sistema de enlaces que constituye la realidad y sus elementos y que el corazón humano refleja. El título mismo del poema, «Creación de la luz», sugiere que la revelación no ocurre espontáneamente sino que implica un trabajo, el que el poema lleva a cabo mediante su tejido verbal. La creación en el título, con la sugerencia de un origen de luz del que todo emanó, adquiere al final un nuevo sentido al comprobarse que todos los elementos de la realidad están implicados en la búsqueda de un origen que, sin embargo, se mantiene en retroceso infinito. La rosa que guía al corazón, signo del misterio del vivir y el arte por antonomasia, retiene su enigma hasta el final: «la rosa / que busca la fuente que 
la ha de liberar del tiempo y del sueño». Como el lirio, la abeja, el fuego, y el corazón, la rosa sigue buscando la fuente originaria que la libere del tiempo, aunque ese origen insista en eludirse.

En «Empiezo donde empieza la palabra» (Intacto asombro 91), el símil anafórico abre la estructura verbal hacia el otro en enlaces llenos de sorpresa (Kristeva 125). Funciona, según define Johnson, como líneas que, procedentes de puntos distantes, confluyen en un mismo lugar ( $\ll$ A simile may be compared to lines converging at a point, and is more excellent as the lines approach from a greater distance» Princeton 768). Además, al asociar elementos sin llegar a identificarlos, el símil da lugar a una desviación o digresión que enfoca la atención en el lenguaje, en la novedad de las asociaciones. Así, la palabra se inicia «como ciervo en la boca», refiriéndonos a la mística donde el ciervo apuntaba a la vía de soledad y pureza (Cirlot 129), símil que se revierte ẹ el verso tres a la palabra «como tierra y llama en la boca del ciervo». Se crea así un proceso de intercambio reflexivo, pues no sólo la palabra se origina en la soledad y silencio de la propia subjetividad, sino también en ese entorno u otro que la palabra quiere articular. Los distintos símiles para la palabra se suceden hasta llegar a la paradoja: «como agua y campo / en la voz, en la incertidumbre de la voz en certidumbre». El carácter indirecto de la paradoja sugiere en su condensación el «concordia discors rerum» horaciano. Situada entre la incertidumbre y la certidumbre, la voz se mueve en esa zona de límites donde los opuestos se funden. De igual modo, la sucesión de tiempos verbales: «como un sueño no cumplido, / como un tiempo ya cumplido, como un silencio que se cumple», marca, de nuevo, el transitar del silencio a la voz, y al proceso que va de uno a otra.

El final del poema es una plegaria a la palabra y al silencio para que la salven «de mi espada en el centro de la espada». Como indicó anteriormente con la cita de Shelley, su poesía es espada porque hiere y porque contiene en sí misma la tendencia a escindir la misma similitud que su tejido verbal busca enlazar. Esa espada divisoria en el corazón mismo de la poesía es «lo oscuro de los nombres que no beben en el silencio». Por tanto, el silencio no es lo que acarrea la escisión de la palabra, sino lo oscuro u opaco de un lenguaje desprovisto de resonancias, impermeable a la red de relaciones que constituyen la Naturaleza. La única salvación, como indica al final, es la palabra: «sólo me salvo en ti donde empiezo como un ciervo, como una fuente, como un sueño en la más clara certidumbre». Recurriendo al símil anafórico y a la paradoja, este poema articula la aventura del lenguaje y su relación con el silencio, y la diferencia entre el silencio, entendido como lo que da a la palabra su sustancia esencial, con el mutismo u opacidad de una palabra que ha perdido su contacto con la vida.

La relación entre voz y escritura, naturaleza y arte se trata en «Piedad» (Intacto asombro 24). El poema es de tipo ecfrástico al dirigirse al grupo 
escultórico de la Piedad, «talla del dolor, yeso cernido en ausencias». La estatua es la petrificación del dolor, la forma artística de una emoción humana que en ella adquiere valor icónico. Al admirar la escultura, exclama: «nunca un canto tan cifrado» se vio antes. Sin embargo, la misma perfección artística de la escultura le hace preguntarse por la vida de dicha representación: ¿qué pasó de sus líquenes y musgo, de su azabache deshojado? El poema parece tener en mente la proximidad entre las dos palabras, piedad y piedra, al preguntarse por la vida de una escultura donde la piedad está petrificada, por lo que desearía cincelarla «en carne cálida y desnuda». En esta meditación sobre la escultura y su conexión con la emoción que representa, la hablante experimenta una «ancha mudanza de la contemplación a lo contemplado». El poema así da forma al límite entre el ojo que mira y el objeto mirado, entre forma y pasión, entre arte y vida. $\mathrm{O}$ entre el fonema y el grafema. Al dirigirse a la escultura mediante el apóstrofe, la hablante está apelando a la voz como presencia para que la vida emerja de su petrificación ${ }^{11}$.

En «Lección de desengaño» (45), la persiana verde en la ventana dejando traslucir la luz por sus rendijas es la representación de la palabra entendida como filtro por el que se entreve el entorno. No hace falta abrir la ventana para ver lo de fuera pues como filtro entre la interioridad subjetiva y el exterior, la persiana/ palabra deja «aprender lo que es igual y lo que es distinto a sí mismo, / a mí, a todo». La palabra apunta a la cosa sin ser la cosa; identifica al sujeto sin ser el sujeto. La palabra, entonces, enseña una lección de desengaño al llamar la atención a la distancia que nos separa de la aprehensión directa del entorno, así como a lo repetitivo de la experiencia al evocarla por la memoria. De raigambre barroca, el desengaño supone la salida del engaño de creer en la posibilidad de captar directamente el entorno, de gozar de una experiencia original, no mediatizada. No hay, sin embargo, desesperación ni angustia en esta constatación, sino placer. Con ecos guillenianos («Cima de la delicia», Cántico), la hablante expresa su delicia al experimentar «la sensación de tiempo» en la tarde que la rodea, gozándose en la «ausencia absoluta» de toda carga del pasado en esa tarde que, repitiendo un proceso temporal, lo renueva constantemente. Frente a la melancolía del retorno becqueriano («Volverán las oscuras golondrinas») ante una repetición temporal que nunca puede recobrar la ex-

${ }^{11}$ En la discusión sobre la escritura y el habla, Derrida cita a Heidegger para quien todas las artes tienen lugar en el espacio poemático, es decir, en el lenguaje. La voz, phoné, es «consciousness itself» ya que al hablar no sólo se es consciente de estar presente, sino de la cercanía propia con el pensamiento o concepto. En la voz se da así la fusión de significante y significado. Frente al reconocimiento tradicional del valor del habla por encima del signo escrito, Derrida destaca el límite en constante funcionamiento entre ambos planos y no su transgresión, lo cual implicaría una superación que no es posible (Positions 11-12, 22). 
periencia humana, el poema de Pujol, por el contrario, goza adivinando la identidad en la repetición, liberándose así de la carga de un pasado irrecuperable. El desengaño de perder el contacto directo es «mies de promesas», pues nos invita a seguir intentando cubrir la distancia que nos separa del entorno y vencer al tiempo. El desengaño enseña, además, que la victoria no es fija ya que tras la fusión viene la disyunción en un proceso constante.

En «Sencillez» (81), «La sencillez es una celosía abierta de palabras / calladas» (81), imagen que recuerda la de la persiana verde, ambas tamices entre lo de dentro y lo de fuera, el yo y su entorno. Aquí la celosía/palabra es una presencia «sencilla», apenas perceptible, pues está abierta en vez de «celar» su interior impidiendo el acceso. Este lenguaje/celosía está formado de palabras calladas, sugerencia del silencio que se encuentra más allá de su articulación. Representa la aspiración de Pujol hacia un lenguaje sencillo y apenas audible, a un ir desnudando las palabras hasta reducirlas a su mínima expresión: «Sencillez es decir tu amado nombre que es como la lluvia». Como imágenes de la palabra, la persiana y celosía no sólo sugieren la presencia material que identifica a la vez que distancia el objeto designado; aluden, también, al enigma del lenguaje por el que el lector se ve obligado a seguir los meandros del texto intentando descifrar su sentido. Como la persiana o celosía, el lenguaje es una red abierta pero a la vez entretejida, con espacios que dejan pasar la luz del sentido pero tras someterlo a un proceso de filtración.

La palabra / persiana o celosía sugiere, además de la mediación implícita en toda experiencia, la necesaria correlación entre la totalidad y el fragmento. Las partes de la persiana o celosía son fragmentos de una totalidad, de igual modo que la palabra es una pieza en el sistema de la significación. Pujol comparte con Zambrano la creencia de que todo es fragmento de un orden total (Muñoz Vitoria 85): «Cada elemento, al mirarlo, es la diferencia con el mundo, / es el fragmento ardiente que al mundo falta para ser completo» («Lección de realidad, de infinitud» 46). Entiende que el fragmento es un centro «donde todo se encuentra y todo es posible», semejante al instante «que equilibra y ordena su antes y el después» y a la palabra, fragmento de la totalidad del sentido pero conteniéndolo en su misma fragmentación. Reconociendo lo particular en lo general y el fragmento en el todo, Pujol desarrolla un entendimiento de la escritura que excluye la creencia en verdades inmutables pues admite lo efímero de su capacidad para retener al tiempo y captar el sentido. Pujol concuerda con la idea de Zambrano para quien el poeta ama la verdad pero no «la verdad excluyente ...imperativa, electora, seleccionadora de aquello que va a erigirse en dueño de todo lo demás, de todo» (Filosofía y poesía 24).

La búsqueda de una palabra callada adquiere una nueva articulación en la imagen de la pared blanca en «Pared blanca, fluyo en voz por vuestro 
silencio» (Intacto asombro 63-64). En su artículo de 1969, «Comunicación sobre el muro», el pintor Tápies explica cómo después de pasar por un período de frenética creación, llenando lienzo tras lienzo de trazos y líneas en total desenfreno, «se abrió de repente un nuevo paisaje, igual que en la historia del que atraviesa el espejo, como para comunicarme la interioridad más secreta de las cosas» (cit. en Amorós, «La retórica del silencio» 18). La pared blanca en el poema de Pujol recuerda la del muro de Tápies como espacio más allá de la representación. Por el silencio de esa pared/hoja en blanco fluye la voz de la hablante inscribiendo sus palabras como trazos con que descifrar el enigma de su blancura. Esa pared/hoja en blanco tiene un valor didáctico y a ella se dirige la hablante para que la adiestre a ver y entender lo que su blancura y silencio encierran. La repetición del verbo «adiestrar» en el poema sugiere la idea de dirigir, además de enseñar, en un espacio que aunque exento de signos incluye todas las posibilidades.

Por eso, en «La vida pasa silenciosa» (85) la hablante afirma: «Soy espejo de la luz, espejo de su calma y de su sombra. / Soy espejo en su espejo, sombra en la memoria de su sombra». Como reflejo de la luz, espejo del espejo que la luz es también, y como reflejo de su reverso en la sombra, la hablante concibe la realidad y el lenguaje como sistemas de cajas chinas en un infinito juego especular donde las diferencias desembocan en la palabra «amor»: «palabra en lo recto y caricia en lo curvo». Tanto palabra como caricia, el amor parece fundir los dos sistemas, el intelectual o del lenguaje, donde la palabra «amor»formaría parte de un proceso lineal en sentido lógico y racional, y el sensorial o del cuerpo donde sería tacto, caricia. Así concluye que: «Amar y amor son ya lo mismo». El verbo amar y su sustantivación en el amor se fusionan dando lugar a la identificación entre abstracción y concreción, lengua y palabra.

Dicha identificación sugiere que la hablante ha llegado a captar el recinto del silencio más allá del límite entre signo y entorno, más allá de la representación. Como Tápies confrontando el silencio de muro de sus lienzos, en «Sabiduría del silencio» (94) la hablante interpela al silencio que, aunque presente en cada forma, no le es posible aprehender: «Existes en todo y en todo te me escapas con un nombre». La urdimbre verbal fracasa en su intento de tejer en sus lazos al silencio cuyo lugar, como más tarde indica, se halla con el amor. Ese es el silencio que busca y quiere la hablante: «Y es éste el silencio que quiero, el silencio sonoro del fuego / por alma y por alma el fuego, y por armonía el gesto del olivo». Ese «silencio sonoro», como la «soledad sonora» o «música callada» de San Juan de la Cruz («Cántico espiritual») es un espacio trascendental más allá del lenguaje lo que, según Steiner (60), espera al poeta que atraviesa los límites del discurso humano, el espacio del amor: «sólo el amor es silencio».

La exaltación del amor se articula en «Amor, hermosa vendimia» (Intacto asombro 18). El poema es un panegírico apostrófico al amor al que 
describe como «silva de resurrección». La referencia a la silva nos devuelve al período del humanismo, y su sentido de bosque frondoso a la poesía de Góngora a cuya variada vegetación verbal se acerca el poema de Pujol. «Hablo y rompo en silencios», afirma la hablante, porque la exuberancia de las imágenes verbales sobre el amor sugiere el carácter dionisíaco de la experiencia que se quiere articular y su extensión más allá de los límites de las palabras. En la «hermosa vendimia» del amor, la hablante corta «palabras como uvas», su voz «se encierra en trillos» y su cuerpo, «se abre en ajimeces que esperan el óleo» de la luz del amor. Los versos se suceden sinuosamente a lo largo de la página en llamadas al amor para que la suba hacia cimas más allá del espacio y del tiempo. Hay también alusiones al Miguel Hernández de El rayo que no cesa («súbeme al vino con tu cuerpo, a lo no herido por el rayo») y de Perito en lunas («súbeme al trigo, al labio en lunas donde contemplar el tiempo»). Sin embargo, la hablante no quiere el amor que Hernández describe como «carnívoro cuchillo» en su poema inicial de $E l$ rayo, sino al amor que la suba a las lunas de una poesía más allá del tiempo.

El carácter dionisíaco de la experiencia se trasluce en la exuberancia verbal de frases laberínticas y direcciones que se cruzan: el subirse es bajarse, palabras y frutas se mezclan, las manos y el alma parecen cruzar los límites que las separan, la realidad se intercambia con el sueño, y el abrirse y cerrarse no se distinguen. El delirio de las palabras crea un asedio para el amor hasta llegar a una cúspide en «ese grito blanco de plumas por el aire, transparencia», eco de la pared blanca en el poema anterior, que es también «grito negro, universo, que alancea entre la nada». La totalidad del amor abarca el espacio blanco más allá de la representación y su contrapartida en lo negro del vacío. De igual modo, el amor puede subirla a alturas más allá del aquí, como bajarla al nivel de lo más elemental.

Este poema, como otros en los dos libros de Pujol, gira en torno del apóstrofe en enumeración acumulativa. Dicho recurso no sólo expresa la intensidad del sentimiento sino, como indica Culler, la atención en el acto de la escritura, del lenguaje: «To apostrophize is to hail a state of affairs, to attempt to call it into being by asking inanimate objects to bend themselves to your desire» (The Pursuit 138, 139). Hay un placer evidente en el decir de las palabras, en su enunciación y fuerza expresiva, pues en su asedio del amor se está estableciendo la identidad de la hablante como poeta (Culler 142) cuya presencia, como voz en el poema, se afirma mediante el apóstrofe y la riqueza de asociaciones metafóricas. Al igual que la anáfora, el apóstrofe extiende el signo hacia el entorno, el «otro», abarcando el espacio de disyunción o vacío entre ambos a la vez que incorporando ese exterior en el interior del poema (Culler 146).

Las dos últimas composiciones de El fuego tiende su aire, «Rosario del hombre» (105) y «Espejo del mundo» (106), también se construyen en torno 
al acto apostrófico del «llamar» que, además, liga ambos poemas como si se trataran de espejos reflejándose entre sí. El primero se lee a modo de rosario o letanía en torno a la repetición anafórica de «llama». «Llamar» supone la identificación de algo o alguien, además de situarnos en el contexto de la poesía como un «llamar» apostrófico al mundo. Para Amorós, el llamar es la manifestación del latir del corazón emergiendo de ese centro como un requerimiento de lo otro («La metáfora del corazón» 49). En el poema de Pujol, la larga serie de versos que constituyen el poema rememora el acto adánico de crear el mundo por el acto de «llamar». Pero en vez de resultar en un mundo claramente definido donde cada cosa tiene su identidad propia, los nombres dados no tienen una conexión exclusiva con el objeto que designan, produciendo el efecto de un contexto donde todo es intercambiable. La identidad no es exclusiva ni definidora sino que todo participa en un juego de intercambio. El poema concluye con la hablante lanzando su llamada para que la llamen, incluyéndose así en el mismo juego de intercambio: «Llámame [...] nombres que no me nombren. / Llámame cofre de brisa cerrada, amor abierto al aire». El poema sugiere un contexto donde el lenguaje se abre en una proliferación de nombres que, o bien son incapaces de captar lo que nombran, o su sentido se mueve a través de contornos y límites no fijos. El último verso: «Llámame cofre de brisa cerrada, amor abierto al aire», expresa el deseo de un nombre/amor que, o bien contenga lo incontenible o se abra a todas las posibilidades.

En «Espejo del mundo», la llamada del poema anterior se refleja aquí en el mundo donde la identidad de las cosas llamadas cambia como sucedería al reflejarse en un espejo. Si en «Rosario del hombre» el hombre llama al amor hierbabuena, en el espejo del mundo el amor/hierbabuena pasa a ser aire/hierbabuena, la vida/bodegón, pasa a ser sueño/bodegón, y así sucesivamente. No sólo la identidad es intercambiable sino que al reflejarse en el mundo, el acto del nombrar acrecienta los reflejos. El libro concluye con una articulación del entorno según el ordo amoris de Scheler donde la identidad se encuentra en un centro como espejo vivo de todo el universo $^{12}$. El poema recrea un «espacio de celebración» donde tiene lugar el conocimiento poético de unas asociaciones que, habiendo estado siempre allí, sólo la poesía ha logrado revelarlas (Moreno Sanz 21, 27, 29).

La sinestesia en el título «Todo huele a silencio» (109), último poema de Intacto asombro, apunta a la captación sensorial de la presencia del silencio en el aire, como si el amor o armonía cósmica se percibiera ahora a modo de recinto sin sonido. Lo olfativo de la sinestesia contrasta con lo abstracto y auditivo del silencio en una imagen que intenta conjuntar los

\footnotetext{
${ }^{12}$ Según Scheler, hay que volver a aprender la «gran solidaridad invisible de todos los vivientes en la 'vida total' de todos los espíritus en el eterno 'Espíritu';» así como la solidaridad «del proceso del mundo con el destino y el devenir de su fundamento, y, viceversa, la del hombre con el proceso del mundo» (152).
} 
planos sensorial e intelectual. La conjunción «Y» con que comienza el poema lo conecta con lo anterior haciendo que todo el libro sea como un poema o meditación continuada. El polisíndeton; «Y es invierno, y el verbo arde lento y breve como el perfume, / y contemplo», comunica el ardor o fuego que ha mantenido este contemplación meditativa, iniciada en «Contemplación primera» (El fuego tiende su aire) y que concluye aquí donde la hablante afirma la misma actitud: «contemplo». Aunque acepta lo vulnerable de su búsqueda meditativa, afirma la claridad que le viene de ella, por lo que pide que le den avena a la contemplación, es decir que la alimenten con los frutos de la tierra para que se infunda de su verdad, pues en la naturaleza reconoce «la piedra de mis sentidos». Como imagen de la eternidad que adquiere lo sensorial en el arte, la piedra supone la fusión de vida y arte.

La conclusión de este libro es una gozosa proclamación de haber tocado el centro: «tiempo de lo eterno en los sentidos». Su contemplación, «libro de rosal y loto», funde el este y el oeste, captando la sabiduría de ambas direcciones. Junto con el verso final del poema, «Es invierno, el verbo arde sereno y todo huele a silencio», la cita de Zambrano con que concluye el libro ( $\ll$ Se escribe para reconquistar la derrota sufrida siempre que hemos hablado largamente») adquiere un sentido nuevo. La escritura del libro supone el triunfo sobre la temporalidad de la palabra aunque el verbo, a pesar de estar fijado en la escritura, siga vivo en su ardor sereno.

Los poemas de Pujol no pueden leerse sólo horizontalmente ya que sus equivalencias metafóricas establecen referencias recíprocas y mutuas entre ellos. En la red de signos que este discurso entreteje entre realidades aparentemente dispares, se sigue la línea epistemológica que desde el Renacimiento considera la similitud como el elemento más universal para acceder al conocimiento (Foucault 29). Con Plotino y San Agustín, Pujol percibe la realidad como una proliferación de signos que esconden a la vez que revelan una verdad superior ${ }^{13}$. Partiendo de la percepción sensorial del mundo, el lector sigue con los ojos la línea curva y continua en que se deslizan los versos en busca de su sentido, en un proceso dinámico de lectura donde se funde lo sensorial, afectivo e intelectual hacia el logro de un conocimiento o estado de conciencia superior. Reconociendo en la línea humanista de un Ficino que el conocimiento al que llega la contemplación procede en un ascenso y descenso, desde el logro del más alto grado en la contemplación hasta la vuelta al plano sensorial, Pujol entiende el balance entre similitud y disyunción que constituye el curso tanto existencial como artístico. Por tanto, se aleja del mutismo que en la década de los sesenta amenazó la obra poética de tantos autores en busca del silencio. Tampoco

${ }^{13}$ En el libro XIII, San Agustín escribe: «There in the heavens, in your Book, we read your unchallengeable decrees, which make the simple learned». 
cae en el solipsismo de la palabra diciéndose a sí misma, ni siente angustia por la dificultad de lograr una unidad de sentido que el juego especular de la palabra impide retener. Su poesía, por el contrario, se mueve en ese límite donde la palabra tiende a su silencio desde sí misma, manteniendo constante la dinámica entre el decir y su acallarse. Si la urdimbre verbal busca entretejer al silencio en sus hilos, el silencio o lo indecible es la base que proporciona sentido a la voz dicha. Pujol deja que la palabra hable, que extienda su potencial en todas las direcciones posibles en un ejemplo de solidaridad de la poeta con sus palabras, de su apertura y receptividad a las variadas e imprevistas asociaciones a que ellas le puedan llevar. Su escritura busca trascender lo que está más allá de su misma urdimbre verbal pero que sólo en ella se configura, y sólo desde ella se puede acceder.

\section{OBRAS CITADAS}

Agustine, Saint, Confessions. Middlesex, England: Penguin, 1961.

AMORós, Amparo, «La retórica del silencio». Los Cuadernos del Norte 16 (NoviembreDiciembre 1982): 18-27.

-, «La metáfora del corazón en la obra de María Zambrano». El pensamiento de María Zambrano. Madrid: Zero, 1983. 39-73.

CIPLIJAUSKAITÈ, Birutè, «Sara Pujol Russell. El fuego tiende su aire». World Literature Today 74.2 (spring 2000). 447.

CIRLOT, Juan-Eduardo, Diccionario de símbolos. Barcelona: Labor, 1985.

Culler, Jonathan, The Pursuit of Signs. Semiotics, Literature, Deconstruction. Ithaca, New York: Cornell UP, 1981.

Dauenhauer, Bernard P., Silence. The Phenomenon and Its Ontological Significance. Bloomington: Indiana UP, 1980.

Derrida, Jacques, Positions. Tr. Alan Bass. Chicago: The U. of Chicago P, 1981.

FouCAult, Michel, The Order of Things. An Archaeology of the Human Sciences. New York: Vintage Books, 1973.

Kristeller, Paul Oskar, The Philosophy of Marsilio Ficino. Tr. Virginia Conant. Glucester, Mass: Peter Smith, 1964.

KristeVA, Julia, Semiotica I. Tr. José Martín Arancibia. Madrid: Fundamentos, 1969.

MANTERo, Manuel, «Carta a Sara Pujol». Epílogo. El fuego tiende su aire. De Sara Pujol Russell. Ferrol: Esquío, 1999. 115-118.

MARTZ, Louis L., The Poetry of Meditation. A Study in English Religious Literature of the Seventeenth Century. New Haven: Yale UP, 1954.

MORENO SANZ, Jesús, «Las fórmulas del corazón». El pensamiento de María Zambrano. Madrid: Zero, 1983. 16-38.

MUÑOZ VITORIA, Fernando, «Sueño y revelación». El pensamiento de María Zambrano. Madrid: Zero, 83-99.

Plotinus, The Enneads. Tr. Stephen MacKenna. London: Faber and Faber, 1956.

Princeton Enlyclopedia of Poetry and Poetics. Ed. Alex Preminger. Princeton, N.J.: Princeton UP, 1974.

Pujol, Sara Russell, Il fuoco del silenzio (El fuego del silencio). Ed. Emilio Coco. Bari: Levante Editori, 2001

-, Intacto asombro en la luz del silencio. Ferrol: Esquío, 2001. 
—, El fuego tiende su aire. Ferrol: Esquío, 1999.

SCHELER, Max, «El porvenir del hombre». Revista de Occidente 17 (julio 1927). 129159.

SHELley, Percy Bysshe, A Defence of Poetry. Ed. John E. Jordan. Indianapolis: The Bobbs-Merrill Co., 1965. 23-80.

STEINER, George, Language and Silence. Middlesex, England: Penguin, 1979.

VALENTE, José Ángel, Las palabras de la tribu. Madrid: Siglo XX de España Editores, 1971.

Zambrano, María, Filosofía y poesía. México: Fondo de Cultura Económica, 1987.

-, Hacia un saber sobre el alma. Madrid: Alianza, 1987.

-, El sueño creador. Madrid: Turner, 1986.

—, Claros del bosque. Barcelona: Seix Barral, 1977. 


\title{
RESUMEN
}

\section{Escribiendo el silencio: la contemplación poética de Sara Pujol, por Can-} delas Gala.

La lectura de El fuego tiende su aire (1999) e Intacto asombro en la luz del silencio (2001) de Sara Pujol Russell, supone la entrada en un discurso poético innovador y complejo tanto en contenido como en forma. Esta poesía invita a una contemplación meditativa que busca las correspondencias entre los diversos elementos de la realidad como clave para acceder a un conocimiento superior. Su escritura se mueve en los bordes entre la voz y el silencio, el arte y la naturaleza, el sentido y el vacío, la identidad y la diferencia, buscando trascender lo que está más allá de su misma urdimbre verbal pero que sólo en ella se configura, y sólo desde ella se puede acceder. En el movimiento de esta escritura por superar la disyunción entre signo y entorno, en esa síntesis a punto de disolverse, es donde se enfoca la lectura en este ensayo.

Palabras claves: amor/amar; anáfora; apóstrofe; armonía; asombro; confluencia; contemplación; continuidad; desengaño; disyunción; entorno; escritura; espejo; éxtasis; fragmento; luz; meditación; mística; nombrar/llamar; paradoja; pared blanca/página en blanco; polisíndeton; reflejo; selva; silencio; silencio sonoro; silva; símil; «similización»; similitud; sinestesia; urdimbre verbal.

\begin{abstract}
Reading Sara Pujol Russell's El fuego tiende su aire (1999) and Intacto asombro de la luz del silencio (2001), is entering into a poetic world whose content and form are both innovative and complex. This poetry invites the reader into a state of meditative contemplation that seeks correspondences among different elements in reality as the key to access a superior type of knowledge. Pujol's writing moves in the fringes between voice and silence, art and nature, meaning and nothingness, identity and difference. it seeks to surpass its own verbal texture while only in that texture does it find articulation and only through it does transcendence becones accessible. The focus of the present reading centers on the point where Pujol's language seeks to transcend the disjunction between sign and surrounding, the point where synthesis is fusion about to dissolve.
\end{abstract}

Keywords: love/to love; anaphora; apostrophe; harmony; wonder; confluence; contemplation; continuity; disillusionent; disjunction; surrounding; writing; mirror; ecstasis; fragment; light; meditation; mysticism; to name/to call; white wall/white page; polysyndeton; reflection; will forest; silence; sonorous silence; silva; simile; «similization»; similitude; synesthesia; verbal weaving. 